\title{
Study on Overseas Luxury Consumption of Chinese Consumers - The Moderating Role of Fashion Difference Perception
}

\author{
Zeli Chai* Nanxi Ning \\ School of Management, Shanghai University, 99 Shang Da Street, Shanghai 200000, China
}

\begin{abstract}
The phenomenon of "inner cold and outer hot" in China's luxury market has attracted the attention of many scholars. Drawing on luxury consumption motivation theory, this article explores the relevant factors influencing Chinese consumers' overseas luxury purchase from multiple dimensions. The results show that three variables, the match degree between country of origins and sales, attached foreign emotional value and the store service, have a positive impact on consumers' attitude towards overseas luxury goods. Only price fairness perception has a negative influence on consumers' attitude towards overseas luxury goods. Furthermore, the effect of price fairness perception on consumers' attitudes towards luxury goods aboard is greater for customers who have a good sense on fashion difference perception.
\end{abstract}

Keywords: luxury consumption motivation, attached foreign emotional value, fashion difference perception, price fairness perception, the match degree between country of origins and sales, store service

DOI: $10.7176 / \mathrm{EJBM} / 11-3-22$

\section{Introduction}

As the growing of the portion that Chinese consumers in the global luxury consumption, China has become one of the world's largest luxury consumption country. According to 《2017 White Paper On China's Luxury Network Consumption》, which is released by temple library the world famous luxury electric business platform, the whole of China luxury goods sales in 2016 was 498.3 billion yuan, accounted for $21 \%$ of global luxury sales, sales ranked second. However, more than $70 \%$ of the luxury consumption did not occur in China, revealing the "consumption outflow" of luxury products is very serious.

With regard to the research in the field of luxury consumption, domestic and foreign research covers the factors of consumers, luxury goods and the consumption environment. However, for some time efficiency and phenomenal luxury consumption behaviors, such as the large-scale overseas luxury consumption of Chinese consumers in recent years, there is still a lack of corresponding research. Especially from the perspective of purchasing motivation, there are few studies on the impact of perceived value on consumers' purchasing behavior. This study aims to supplement the gaps in this research field. Based on the theory of luxury purchase motivations, this paper explores which factors affect the perceived value in the process of forming the purchase intentions of overseas luxury goods. Further analyse the main factors and mechanisms that affect the overseas luxury consumptions and providing reference for the luxury marketing strategy.

\section{Literature Review}

\subsection{Definition of Luxury}

For the definition of luxury goods, domestic and foreign researches have not reached a unified standard. Partly because of the development and changes of the social and economic environment, people's understanding for luxury goods is also constantly adjusting. On the other hand, due to differences in history and culture, the concept of luxury goods cannot be uniformly measured by the same standard. The definition of luxury by Bagwell and Bernheim (1996) are recognized as the most accept one: luxury goods are considered to be honoured by consumers who own, wear (Han et al. 2010) and consumption (Kim \& Lee 2015) product or service. The main characteristics of luxury goods are: the price is extremely expensive, the quality is extremely high, and at the same time it is both scarce and unique. Luxury goods are not essential products and services for life and are non-essential items.

\subsection{Research on Purchasing Motivation of Luxury Goods}

Studies of luxury purchasing motivation is mainly carried out from two aspects-individual-oriented value and 
social-oriented value. Personal orientation includes functional value, experiential motivation (Vickers \& Renand 2003), uniqueness value, quality value, extension ego (Vigneron \& Johnson 2004), hedonic value, pursuit of refinement (Dubois et al. 2015), material enjoyment, group communication and self-coordination (Marcoux et al. 1997). From the social orientation value level, the conspicuous value of luxury goods) allows consumers to show off their wealth and status (Dogan et al. 2018). The uniqueness of luxury goods enables consumers to get the unique value and experience. In addition, consumers may buy luxury products to gain social recognition, so conformity is also one of the purchasing motives of luxury products (Zeng 2006).

Many studies have shown that consumers' motivation to purchase luxury goods is more a comprehensive manifestation of the combination of social orientation and personal orientation value (Vickers \& Renand 2003; Luo 2014). For example, when Marcoux et al. (1997) studied the attitudes of polish consumers towards western products, they found that consumers' purchasing motivation is the comprehensive expression of the two socially oriented dimensions of conspicuous consumption and social status, as well as the three individual value dimensions of material enjoyment, group communication and self-relation coordination. In addition, domestic scholar Guo (2007) also found that the luxury consumption motivation of young white-collar workers is a comprehensive manifestation of society and individual, including showing off, status symbol, uniqueness, internal consistency, quality refinement and self-gift.

\subsection{Luxury Management and Brand Culture}

Researches on luxury management and brand culture mainly include the related theories of establishment and management of luxury brand. The establishment of luxury brands is an integrated system (Beverland 2005), which contains a series of factors: excellent products, history, culture, fine marketing, social identity; design and communication management, product line management, customer service management and channel management are the four most basic and key factors for the successful operation of luxury products.

\subsection{Research on Relevant Factors Influencing Consumers' Purchasing Luxury Goods}

The research on relevant factors influencing luxury purchase is carried out from three aspects, including individual factors, product factors and social factors. Consumers' attitudes towards luxury goods are largely related to personal statistical factors, lifestyle, habits and social environment (Dubois et al. 2005; Tidwell \& Dubois 1996), including income, age, gender, marital status, and family composition. In general case, consumers are only likely to consider purchasing luxury when they have disposable income, so the rapid growth of luxury market depends largely on the income level of consumers (Kivenzor \& Toffoli 2016; Mitchell 2014). Traditionally, consumers of luxury goods are more concentrated in the people between 30 and 50 years old, who are relatively independent in economy. However, the market situation in recent years shows that the consumers of luxury goods are gradually younger. Therefore, age is also a major factor influencing the consumption of luxury goods.

The factors influencing consumers' purchase of luxury products mainly include price, function and quality. In general, the lower the price of products, the better. However, in terms of luxury consumption, consumers pay more attention to value rather than price (Lichtenstein et al. 1990). Although luxury goods are regarded as the least cost-effective products in the market, the benefits they bring, especially from the perspective of psychological satisfaction, can still make numerous luxury brands popular among the public (Belk 1988). In addition, the product quality of luxury products also plays an important role in consumer's consumption behavior. In China, luxury usually represents more perfect functions and superior quality.

\section{Theoretical Framework and Research Hypothesis}

Based on the Howard \& Sheth model (1971), this paper argues that the behavior of Chinese consumers buying luxury goods abroad is based on external factors including culture and consumer personality, as well as inputs related to luxury goods themselves. Variables (such as product substance, product symbol, social stimulus), these two factors affect the consumer's psychological activity process, which ultimately affects the consumer's purchase behavior. 


\subsection{Price Fairness Perception and Attitude Towards Luxury Goods}

The concept of price fairness comes from an objective comparison between the selling price of a merchant and the price of other merchants in the same industry (Xia et al. 2004). Price fairness perception can be defined as whether the consumer's price difference between the merchant and its competitors is reasonable, acceptable, and evidence-based to form perceptions and associated sentiments (Kukar- Kinney et al. 2007).

In the field of luxury consumption, due to the opaqueness of merchant profits and the significant differences in pricing of countries, consumers have obstacles in subjective perception of price fairness. Therefore, the comparison of absolute value of prices has greatly affected consumers. Chinese consumers are becoming more sensitive to the perception of the spread between the mainland and overseas luxury markets, and the tolerance for spreads is getting lower and lower. Hence, the following hypotheses are advanced.

Hypothesis 1: Price fairness perception negatively affects consumers' attitudes towards luxury goods.

\subsection{The Match Degree Between Country of Origins and Sales and the Attitude of Consumers Towards Luxury Goods}

The country of origin (Country-of-Origins) can be seen as the country in which a product is produced or assembled (Lee 2009). Roth \& Romeo (1992) were the first scholars to use the national image to explain the characteristics of the country of origin. They defined the national image as a picture, a reputation, or an impression that hurts, and consumers are inherent in a country's products. This national image is built from the representative products of a country, such as national characteristics, economic and political background, history and tradition (Nagashima 1970). In the process of luxury consumption, due to the asymmetry of consumers' own information, consumers tend to make predictions based on some thought shortcuts, and the image of the country of origin of the product will have a significant impact on consumer prediction.

Yucetepe \& Veysel (2003) introduced a new concept in the study of the country of origin: Country-ofDestination, the country in which the market for the final sale of a product is located. Their results show that the seller country has a major effect on product evaluation, and the seller country adjusts the impact of the country of origin on product evaluation.

Based on the above analysis, both the sales country effect and the country of origin effect have a significant impact on consumers' willingness to purchase. This paper combines the two factors of the sales country effect and the country of origin effect, and innovatively proposes the seller country and the variable of the country of origin is based on the scholars' research on the consumer-country effect and the country of origin effect on consumer evaluation of products. Hence, the following hypotheses are advanced.

Hypothesis2: The match degree between country of origins and sales is positively affecting consumers' attitude towards luxury goods.

\subsection{Attached Foreign Emotional Value and Attitude Towards Luxury Goods}

The variable of attached foreign emotional value is based on the ostentatious value of luxury goods and social value. The introduction of this variable fully refers to the behaviour of the current Internet to display luxury goods on its live platform. Many web celebrities showcase their luxury goods in their own channels, while also emphasizing the special experience of buying them abroad. They over-exclusive the luxury purchase process to the individual's experience of traveling, working or learning abroad, which in turn gives social value to the luxury goods purchased abroad.

In the actual research process, it was found that this variable has almost no similar appearance in the literature. After discussion with experts, this research decided to refer to Yang et al. (2011) for overseas study experience and cross-cultural experience for international students. Positive impact, the attached foreign emotional value is described as a perceived emotional value and then analysed as the perceived dimension of luxury goods. Hence, the following hypotheses are advanced.

Hypothesis 3: Attached foreign emotional value positively affects consumers' attitudes towards luxury goods.

\subsection{Store Services and Attitudes Towards Luxury Goods}

Luxury goods have high consumption risks due to their high pricing attributes. Whether recognized by the social group it belongs reflects the conspicuous value, which is an important factor in the process of potential 
consumers to form purchase intentions. Increasing consumer enjoyment in store services can effectively reduce perceived consumer risk and improve overall consumer experience (Julian \& Ramasehan 1994).

Bruce \& Kratz (2007) pointed out in the study that retail store management and product design and marketing are the core competitive areas of luxury goods companies. The store retail experience is gradually increasing in importance among the three, one of the main reasons is consumption. The emotional state of the store is influenced by it and further influences its attitude towards consumption and willingness to purchase (Jones et al. 2006). Therefore, major luxury brands are more inclined to carefully design the consumer experience.

Hence, the following hypotheses are advanced.

Hypothesis 4: Store services positively affects consumers' attitudes towards luxury goods.

\subsection{The Moderating Role of Fashion Difference Perception}

Consumers follow the trend and fashion in order to get the attention of others. In the process of pursuing conspicuous value consumption, product brand and economic value are more important than the functional value of the product. Its role is to highlight individual wealth. And taste (Truong et al. 2008). Luxury consumers often consider the recognition of taste and social groups as an important consideration. This perception of buying luxury goods is also a way for them to improve their sense of belonging or to enter a social group. Due to group culture, Chinese consumers consider the opinions of social groups and brand awareness as an important consideration in the process of making luxury consumption decide (Amatulli \& Guido 2012).

Combined with previous studies, consumers' perception of fashion positively influences the evaluation of consumer products. According to the analysis of the current situation of Chinese consumers' overseas luxury purchases, combined with a large number of news and interviews, Chinese consumers are interested in domestic and foreign fashion luxury goods. Therefore, based on the variable of fashion level, this paper extracts the variable of domestic and foreign fashion differences perception, and explores whether the fashion differences perception has a regulatory effect in the process of purchasing motivation to purchasing attitude.

Hence, the following hypotheses are advanced.

Hypothesis 5a: Fashion differences perception negatively affects the impact of price fairness perception on consumer attitudes.

Hypothesis 5b: Fashion differences perception positively affects the impact of the match degree between country of origins and sales on consumer attitudes.

Hypothesis 5c: Fashion differences perception positively affects the impact of attached foreign emotional value on consumer attitudes.

Hypothesis 5d: Fashion differences perception positively affects the impact of store services on consumer attitudes.

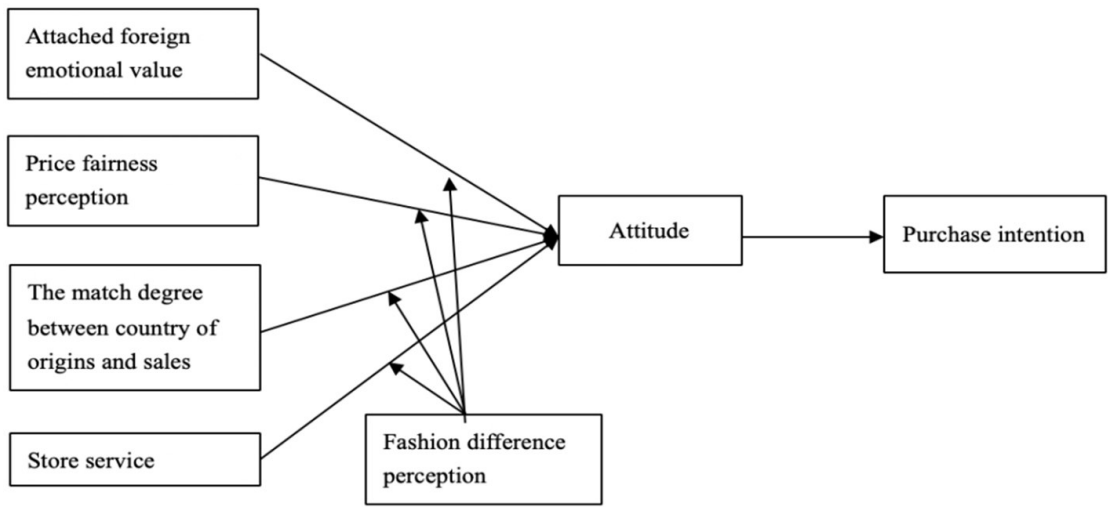

Figure 1. Research Model

\section{Research Methods}

\subsection{Measurement}

This study involves seven variables, including price fairness perception, fashion differences perception, match 
degree between country of origins and sales, attached foreign emotional value, store service, consumer attitude towards luxury goods, purchase intention for luxury goods. In order to better test difference in all variables on the individuals' level, the measurement scales of this study are adapted from previous studies.

All items of scale used for measuring sub-dimensions adopt seven-point Likert-type scale ranging from 1(strongly disagree) to 7(strongly agree). Finally, 150 samples are collected by random sampling in the target groups. The results of pretest state that questionnaires have good reliability and validity.

\subsection{Sample Data Collection}

The main sample of this study is office workers who have economic foundation. By the intercepting visits and online survey method to collect questionnaire, there are 434 valid questionnaires. See Table 1. for details.

Among the randomly selected samples, there were 200 males and 234 females. In terms of age distribution, the respondents' ages of 26-30 years old and 31-40 years old accounted for 59.4\% of the total samples, which is consistent with the age of the study participants. Therefore, the sample structure of this study is more reasonable.

Table 1. Formal Investigated Sample Descriptive Statistics.

\begin{tabular}{|c|c|c|c|}
\hline \multicolumn{4}{|c|}{ Sample Characteristics $(\mathrm{N}=434)$} \\
\hline Variables & Category & Frequency & Proportion\% \\
\hline \multirow{2}{*}{ Sex } & A: male & 200 & 46.08 \\
\hline & B: female & 234 & 53.92 \\
\hline \multirow[t]{6}{*}{ Age } & $\mathrm{A}: \leq 25$ & 86 & 19.82 \\
\hline & $\mathrm{B}: 26 \sim 30$ & 140 & 32.26 \\
\hline & $\mathrm{C}: 31 \sim 40$ & 118 & 27.19 \\
\hline & $\mathrm{D}: 41 \sim 50$ & 59 & 13.59 \\
\hline & $\mathrm{E}: 51 \sim 60$ & 28 & 6.45 \\
\hline & $\mathrm{F}:>60$ & 3 & 0.69 \\
\hline \multirow[t]{5}{*}{ Monthly Income } & $\mathrm{A}: \leq 10 \mathrm{w}$ & 85 & 19.59 \\
\hline & $\mathrm{B}: 10 \mathrm{w} \sim 30 \mathrm{w}$ & 155 & 35.71 \\
\hline & $\mathrm{C}: 30 \mathrm{w} \sim 50 \mathrm{w}$ & 151 & 34.79 \\
\hline & $\mathrm{D}: 50 \mathrm{w} \sim 100 \mathrm{w}$ & 34 & 7.83 \\
\hline & $\mathrm{E}:>100 \mathrm{w}$ & 9 & 2.07 \\
\hline \multirow[t]{5}{*}{ Education Degree } & A: High school or below & 45 & 10.37 \\
\hline & B: Junior college & 99 & 22.81 \\
\hline & C: Undergraduate & 206 & 47.47 \\
\hline & D: Master & 76 & 17.51 \\
\hline & E: Dr and above & 8 & 1.84 \\
\hline
\end{tabular}

\section{Results}

\subsection{Reliability and Validity Analysis}

This study uses SPSS and AMOS to examine measurement model's reliability and validity. Table 2 presents that all of the Cronbach's $\alpha$ of the observation variables are greater than 0.7 , which reveals high reliability. Meanwhile, the factors loading of all sub-dimensions exceed the cut-off value of 0.5 and the average variance extracted (AVE) of latent variables are above 0.5 in magnitude. In summary, these results provide evidence to manifest convergent validity of scale. 
Table 2. Factor Loading, Alpha Coefficient, CR, AVE

\begin{tabular}{|c|c|c|c|}
\hline Latent Variables & Observation Variables & $\begin{array}{l}\text { Factors } \\
\text { Loading }\end{array}$ & $\begin{array}{l}\text { Cronbach's } \\
\alpha\end{array}$ \\
\hline \multirow{4}{*}{$\begin{array}{l}\text { Price fairness } \\
\text { perception }(\mathbf{P P}) \\
\mathrm{CR}=0.897 \\
\mathrm{AVE}=0.685\end{array}$} & $\begin{array}{l}\text { pp1: when buying a luxury, I will buy it in a cheaper } \\
\text { country. }\end{array}$ & 0.81 & \multirow{4}{*}{0.89} \\
\hline & $\begin{array}{l}\text { pp2: When I choose luxury, price is an important factor } \\
\text { I consider. }\end{array}$ & 0.85 & \\
\hline & $\begin{array}{l}\text { pp3: The reason why I buy luxury goods overseas is } \\
\text { because the price of this product is cheaper than in } \\
\text { China. }\end{array}$ & 0.78 & \\
\hline & $\begin{array}{l}\text { pp4: When buying luxury goods, I will compare the } \\
\text { prices of the same products in different countries. }\end{array}$ & 0.86 & \\
\hline \multirow{6}{*}{$\begin{array}{l}\text { The match degree } \\
\text { between country of } \\
\text { origins and sales } \\
\text { (MD) } \\
\text { CR }=0.895 \\
A V E=0.588\end{array}$} & $\begin{array}{l}\text { md: I think that luxury goods purchased in countries } \\
\text { with good quality images have quality that matches } \\
\text { them. }\end{array}$ & 0.79 & \multirow{6}{*}{0.89} \\
\hline & $\begin{array}{l}\text { md2: I think that luxury goods purchased in countries } \\
\text { with good quality images are better than luxury goods } \\
\text { purchased in countries with poor quality images. }\end{array}$ & 0.79 & \\
\hline & $\begin{array}{l}\text { md3: I believe that the pursuit of excellence in quality } \\
\text { has a long history in countries with good quality } \\
\text { images. }\end{array}$ & 0.84 & \\
\hline & $\begin{array}{l}\text { md4: When buying overseas, I will pay attention to the } \\
\text { origin of the luxury goods. }\end{array}$ & 0.68 & \\
\hline & $\begin{array}{l}\text { md5: I think that the products produced by countries } \\
\text { with good quality image are excellent. }\end{array}$ & 0.74 & \\
\hline & $\begin{array}{l}\text { md6: When buying luxury goods in a country with a } \\
\text { good quality image, I would be happy to buy the } \\
\text { country of origin as well as the country's products. }\end{array}$ & 0.76 & \\
\hline \multirow{4}{*}{$\begin{array}{l}\text { Attached Foreign } \\
\text { Emotional Value } \\
\text { (AE) } \\
C R=0.896 \\
A V E=0.683\end{array}$} & $\begin{array}{l}\text { ae1: The experience of buying luxury goods overseas } \\
\text { will prompt me to recognize and adjust my views on } \\
\text { luxury goods. }\end{array}$ & 0.85 & \multirow{3}{*}{0.89} \\
\hline & $\begin{array}{l}\text { ae2: Some of my habits of buying luxury goods will be } \\
\text { affected by the previous experience of buying luxury } \\
\text { goods abroad. }\end{array}$ & 0.82 & \\
\hline & $\begin{array}{l}\text { ae3: When I see the luxury goods I bought overseas, it } \\
\text { will remind me of some special memories. } \\
\text { (for example, traveling, studying or business trips } \\
\text { abroad, or simply recalling the place of purchase) }\end{array}$ & 0.83 & \\
\hline & $\begin{array}{l}\text { ae4: I feel that it is especially fun to buy luxury goods } \\
\text { overseas. }\end{array}$ & 0.81 & \multirow{4}{*}{0.85} \\
\hline \multirow{3}{*}{$\begin{array}{l}\text { Attitude towards } \\
\text { luxury goods }(A T) \\
C R=0.853 \\
A V E=0.659\end{array}$} & $\begin{array}{l}\text { at1: I think the quality of the services provided by the } \\
\text { sales staff of overseas luxury goods stores is very high. }\end{array}$ & 0.80 & \\
\hline & $\begin{array}{l}\text { at2: I would highly appreciate the overall environment } \\
\text { of overseas luxury stores. }\end{array}$ & 0.84 & \\
\hline & $\begin{array}{l}\text { at3: I have a great experience when I shop at an } \\
\text { overseas luxury store. }\end{array}$ & 0.79 & \\
\hline \multirow{3}{*}{$\begin{array}{l}\text { Purchase intentions } \\
\text { (PI) } \\
\mathrm{CR}=0.871 \\
\mathrm{AVE}=0.693\end{array}$} & $\begin{array}{l}\text { pil: I feel good about the overall service provided by } \\
\text { the overseas luxury goods store to consumers. }\end{array}$ & 0.80 & \multirow{3}{*}{0.87} \\
\hline & pi2: I think overseas luxury products are worth buying. & 0.84 & \\
\hline & pi3: In general, I am very willing to buy luxury goods & 0.85 & \\
\hline
\end{tabular}




\begin{tabular}{|l|l|l|l|}
\hline Latent Variables & Observation Variables & $\begin{array}{l}\text { Factors } \\
\text { Loading }\end{array}$ & $\begin{array}{l}\text { Cronbach's } \\
\alpha\end{array}$ \\
\hline & abroad. & & \\
\hline $\begin{array}{l}\text { Store service (SE) } \\
\text { CR }=0.854 \\
\text { AVE }=0.594\end{array}$ & $\begin{array}{l}\text { se1: I think the quality of the services provided by the } \\
\text { sales staff of overseas luxury goods stores is very high. }\end{array}$ & 0.75 & \multirow{2}{*}{0.85} \\
\cline { 2 - 3 } & $\begin{array}{l}\text { se2: I would highly appreciate the overall environment } \\
\text { of overseas luxury stores. }\end{array}$ & 0.78 & \\
\cline { 2 - 3 } & $\begin{array}{l}\text { se3: I have a great experience when I shop at an } \\
\text { overseas luxury store. }\end{array}$ & 0.76 & 0.79 \\
\cline { 2 - 3 } & $\begin{array}{l}\text { se4: I feel good about the overall service provided by } \\
\text { the overseas luxury goods store to consumers. }\end{array}$ & 0 \\
\hline
\end{tabular}

\subsection{Hypothesis Test}

To further verify the causal relationship between the variables, this study uses AMOS to apply structural equation models to the research hypothesis. Verification is performed to obtain the path coefficient of the structural equation model of Fig. 1.

From Table 3, it can be seen that CMIN/DF is 1.828 , less than 3, GFI $=0.920$, AGFI $=0.901$, NFI $=0.932$, $\mathrm{TLI}=0.963$, IFI $=0.968, \mathrm{CFI}=0.968$, all of which meet the standard of 0.9 or higher, RMSEA is 0.044 , which meets the standard of 0.08 or less, most of the fitting indicators are in line with the general SEM research standards, so it can be proved that this model has a good fit.

Table 3. Structural Equation Model Fitting Index

\begin{tabular}{lllllllllll}
\hline & CMIN & DF & CMIN/DF & GFI & AGFI & RMSEA & IFI & NFI & TLI(NNFI) & CFI \\
\hline Standard & & & $<3$ & $>0.9$ & $>0.9$ & $<0.08$ & $>0.9$ & $>0.9$ & $>0.9$ & $>0.9$ \\
Fitting Results & 440.66 & 241 & 1.828 & 0.92 & 0.901 & 0.044 & 0.968 & 0.932 & 0.963 & 0.968 \\
\hline
\end{tabular}

Table 4 presents that the standardization coefficient of price fairness perception to consumers' attitude is $\beta=-0.266(\mathrm{P}<0.05)$, indicates that price fairness perception has significant negative effect on consumer attitude, H1 is proved; the standardization coefficient of the match degree between country of origins and sales to consumer's attitude is $\beta=0.266(\mathrm{P}<0.05)$, indicating that the match degree between country of origins and sales have a significant positive impact on customers attitudes, $\mathrm{H} 2$ is proved; the standardization coefficient of attached foreign emotional value to consumers' attitude is $\beta=0.147(\mathrm{P}<0.05)$ indicates that attached foreign emotional value has a significant positive impact on customers attitudes, $\mathrm{H} 3$ is proved; the standardization coefficient of store service to consumers' attitude towards luxury goods is $\beta=0.257(\mathrm{P}<0.05)$ indicates store services have a significant positive impact on consumers' attitude, $\mathrm{H} 4$ is proved; the attitude towards luxury goods has a standardized coefficient of purchase $=0.612(\mathrm{P}<0.05)$ standard, indicating that the attitude towards luxury goods have a significant influence on purchase willing, H6 is proved.

Table 4. The Results of Hypothesis Testing

\begin{tabular}{|l|c|c|c|c|}
\hline Hypothesis & Standardized Path Coefficient & T-value & P & Result \\
\hline H1: PP---AT & -0.266 & -4.957 & $* * *$ & Accepted \\
\hline H2: MD---AE & 0.226 & 3.978 & $* * *$ & Accepted \\
\hline H3: AE---AT & 0.147 & 2.645 & 0.008 & Accepted \\
\hline H4: SE---AT & 0.257 & 4.285 & $* * *$ & Accepted \\
\hline H5: AT---PI & 0.612 & 10.778 & $* * *$ & Accepted \\
\hline
\end{tabular}

\subsection{The Moderating Role of Fashion Differences Perception}

This paper uses the method of hierarchical regression analysis to test the adjustment effect of fashion difference perception on the price fairness perception, attached foreign emotional value, the match degree between the country of origins and sales, and the service difference of overseas luxury store. The result is as Table5 shows. 
Table 5. The Results of Moderating Effect Testing

\begin{tabular}{|l|l|l|l|l|}
\hline & \multicolumn{2}{|l}{ Dependent Variable (consumer purchase attitude) } \\
\hline & Model 5-1 & Model 6-2 & Model 6-3 & Model 6-4 \\
\hline Variable & $\beta$ & $\beta$ & $\beta$ & $\beta$ \\
\hline Intercept) & $4.64259^{* * *}$ & 0.2320 & 1.015373. & 0.9390 \\
\hline Gender & -0.0943 & 0.0315 & 0.0499 & 0.0358 \\
\hline Age & $-0.11036^{* *}$ & -0.04828. & -0.0439 & -0.047352. \\
\hline Income & $0.17302^{* *}$ & $0.147723^{* * *}$ & $0.13415^{* * *}$ & $0.141827^{* * *}$ \\
\hline Edu & 0.0682 & 0.0033 & -0.0033 & -0.0072 \\
\hline Perception & & -0.0155 & $-0.201024^{*}$ & -0.0657 \\
\hline Value & & $0.23683^{* * *}$ & $0.21714^{* * *}$ & -0.1271 \\
\hline Match & & $0.166813^{* * *}$ & $0.135^{* *}$ & -0.1639 \\
\hline Service & & $0.499858^{* * *}$ & $0.471505^{* * *}$ & $1.030634^{* * *}$ \\
\hline Differ & & & -0.0697 & -0.0672 \\
\hline Perception*Differ & & & 0.036453. & 0.0078 \\
\hline Value*Differ & & & & 0.076186. \\
\hline Match*Differ & & & & 0.066838. \\
\hline Service*Differ & & & & $-0.121353^{* * *}$ \\
\hline F & $5.442^{* * *}$ & $53.87 * * *$ & 0.6163 & $54.56^{* * *}$ \\
\hline $\mathrm{R}^{2}$ & 0.0484 & 0.6026 & 0.6287 \\
\hline
\end{tabular}

This paper proposes innovatively that price fairness perception may affect the attitude of consumers to luxury purchases under the influence of fashion differences perception. The regression results of Model 5-3 verify the above view. After adding the intersection of fashion differences perception and fashion differences perception and price fairness perception, the coefficient of price fairness perception is significantly -0.201024 , indicating that if consumers feel that domestic prices are higher relative to foreign countries (reflecting unfairness), they are more inclined to purchase luxury goods abroad. If consumers feel that domestic prices are lower relative to foreign countries, they are more inclined to Buy luxury goods domestically. In Model 5-3, the regression outcomes of attached foreign emotional value, the match degree between country of origins and sales and the store service are still significant. The cross-terms of fashion differences perception and price fairness perception are significant at the level of $10 \%$. It can be seen from Table 5 that the $\mathrm{R}^{2}$ of the model 5-3 is 0.6163 , which is 0.139 higher than the $\mathrm{R}^{2}$ of the model 2 and has a better explanatory power.

To further test whether the fashion difference perception affects the other three explanatory variables, we add the intersection of the four explanatory variables to the model 5-4 relative to model 5-2. It can be seen from Table 5 that although the $\mathrm{R}^{2}$ of the model 5-4 is improved, the regression results of the variables are not good, indicating that the fitting degree of the model is not good. In summary, the price fairness perception has a significant impact on consumers' attitude towards luxury purchases under the influence of fashion differences perception.

\section{Discussion and Conclusion}

Based on the existing research, this paper focuses on the Chinese consumer's consumption behavior of luxury goods, and uses expert interviews, questionnaires, empirical tests and other methods to draw the following conclusions:

(1) The consumer groups that buy luxury goods overseas are gradually getting younger. In the hierarchical regression analysis with gender, age, income, and education (Edu) as independent variables, it can be seen from the statistical results of Model 5-1 in Figure 6 that age and income are at 1\%. The level is significant, while the control variable gender and educational background are not significant, and the age coefficient is significantly 0.11036 , the sign is negative, indicating that the older the age, the less interested in buying luxury goods, and the age the smaller the attitude, the more positive the attitude towards the purchase of luxury goods. It reflects that Chinese young people now have a higher degree of recognition of luxury goods and a more positive attitude towards the purchase of luxury goods. This is also closely related to the growth experiences of these generations 
in China. Most of the surveyed people over the age of 40 have experienced the poor life before the reform. They are relatively frugal in their lives, and most of the people under the age of 40 , especially those under the age of 30 , were born after the reform and opening up. Their growth environment is much richer than the previous generation. Therefore, their consumption concept is very different from that of the previous generation, and their attitude towards luxury consumption is relatively positive. The above regression results also support this reality.

(2) The variable about the price fairness perception has a negative impact on consumers' willingness to purchase luxury goods, assuming $\mathrm{H} 1$ is verified. This shows that if consumers feel that domestic prices are higher relative to foreign countries (reflecting unfairness), the more positive consumers are toward foreign luxuries, the more they are inclined to buy luxury goods abroad. If consumers feel that domestic prices are lower relative to foreign countries, the more negative consumers are about buying luxury goods abroad, the more they prefer to buy luxury goods in China.

(3) Regarding the match degree between the country of origins and sales, it has a positive impact on consumers' willingness to purchase luxury goods, assuming $\mathrm{H} 2$ is verified. This shows that the higher the matching degree between the luxury goods origins country and the country of sales, the more positive the attitude of consumers to purchase luxury goods abroad.

(4) Regarding the attached foreign emotional value, it has a positive impact on consumers' willingness to purchase luxury goods, $\mathrm{H} 3$ is verified. This shows that the better the experience of buying luxury goods abroad, the more consumers are willing to buy luxury goods abroad, the good experience of consumers has a good impression, which promotes this positive cycle; The worse the experience of buying luxury goods abroad, the lower the willingness of consumers to buy luxury goods abroad.

(5) Regarding store services, it has a positive impact on consumers' willingness to purchase luxury goods, assuming $\mathrm{H} 4$ is verified. This shows that if consumers can get better services in overseas luxury stores, consumers have a stronger willingness to buy luxury goods abroad; on the contrary, if consumers can get better services in domestic luxury stores, consumption Those have a stronger willingness to buy luxury goods in the country.

(6) The test of the moderator variable of fashion differences perception shows that the fashion difference perception negatively moderator the influence of price fairness perception on the consumer's attitude toward the purchase of luxury goods, assuming that $\mathrm{H} 5 \mathrm{a}$ is verified. Price fairness perception has no significant impact on consumers' purchasing attitude towards luxury goods, but after adding the fashion differences perception, price fairness perception shows a significant negative effect on consumer's attitude toward luxury goods.

(7) The results of the study show that consumers' attitudes towards overseas luxury goods have a positive impact on consumers' willingness to purchase luxury goods, and $\mathrm{H} 6$ has been verified, which is consistent with the previous conclusions (Ajzen \& Fishbein 1975). The attitude of a luxury brand, or a luxury consumption environment in a certain country, consumers will not change their attitudes at will. Because of this attribute of attitude, it is often considered a prerequisite for relatively stable and long-term consumer behavior.

\section{Management Implications}

(1) Implications for government management

The relevant departments of the Chinese government can be upgraded from the following aspects. First, reasonable control of import tariffs, so as price differences between domestic and overseas should be further eliminated to avoid blind overseas luxury consumption. Second, strictly control the quality of products from the national level, and then reshape the image of "Made in China" enhances the confidence of the country name in "Made in China".

(2) Management implications for Chinese companies

Domestic enterprises need to be awakened. As a big consumer of luxury goods, the vast majority of consumption occurs outside the country, indicating that Chinese consumers are dissatisfied with domestic luxury goods. Chinese companies can improve from the following aspects: First, improve product quality, this is the basis of the product; second, to improve service quality, Chinese companies should pay attention to the improvement of service levels, create a good purchasing environment and services, and enhance consumers' willingness to purchase; Strengthen the investment and attention to origins design, learn the importance of foreign luxury brands for design, enhance the origins strength, and combine Chinese characteristics to make "luxury goods" 
belonging to China.

(3) Management implications for foreign luxury goods manufacturers

During the winter of the global luxury goods market, the strong purchasing power of Chinese consumers is still only increasing. The Chinese market is definitely one of the most important markets for major luxury brands, facing the Chinese luxury market. A phenomenon, foreign luxury goods manufacturers can think from the following perspective: For the same brand, where consumers consume is a revenue for the brand, so if Chinese consumers are more willing to buy luxury goods abroad, then the responsibility of Hua endian is not necessarily sales. Foreign luxury goods manufacturers can strengthen the brand promotion in the Chinese market, such as selecting a topical artist to carry out bundled publicity and vigorously advertising on various media platforms. Marketing strategies to enhance the image of their brands, and thus attract more Chinese consumers to go abroad to buy luxury goods.

\section{Limitations and Future Research}

Based on the previous studies, this thesis combines the theory of luxury purchase motives with Chinese consumers as the research object to construct a model that influences consumers' willingness to purchase luxury goods, and conducts hypothesis testing through empirical research, but due to scientific research methods. The scientific research conditions and my research ability are limited, and the related references are few. The research has certain limitations, including the following aspects:

(1) Because of the high price of luxury goods, the respondents may have a longer span of the last purchase of luxury goods and the time of investigation. The memory of consumers' shopping experience of luxury goods may be forgotten, and the feeling is not as good as before. Direct and clear, will affect the respondent's evaluation of the luxury shopping experience to a certain extent; and the method of questionnaire survey is easy to make consumers feel tired of resistance, cannot fully reflect the true attitude of consumers to the purchase of luxury goods, and thus will Affect the accuracy of the final research conclusions.

(2) Most of the research samples are from consumers in Shanghai, and the sample groups are mostly young students and white-collar workers, which will affect the universality and promotion of conclusions; and demographic characteristics such as age, gender, Occupation, income, etc., lack of in-depth analysis, did not fully analyze the impact of consumers of different status levels on the willingness to purchase luxury goods.

(3) In addition, the modulating variables in this paper are perceived fashion differences, and in this study, only the influence of mediating variables and dependent variables is adjusted, and the research is relatively simple; while the whole model is comprehensive, the market perception of Zen may also affect Consumers' attitudes toward luxury purchases have an impact on the relationship between consumers' willingness to purchase luxury goods.

\section{References}

Ajzen, I. , \& Fishbein, M. . (1975). A bayesian analysis of attribution processes. Psychological Bulletin, 82(2), 261-277.

Amatulli, C., Guido, G.(2012), Externalised vs. internalised consumption of luxury goods: propositions and implications for luxury retail marketing[J]. International Review of Retail Distribution \& Consumer Research, 22(2):189-207.

Bagwell, L. S., \& Bernheim, B. D. (1996). Veblen effects in a theory of conspicuous consumption. American Economic Review, 86(3), 349-373.

Belk, R.W. (1988), Possessions and the extended self [J]. Journal of Consumer Research, 15(2):139-168.

Beverland M. (2005), Brand management and the challenge of authenticity[J]. Journal of Product \& Brand Management, 14(7):460-461.

Bruce M., Kratz C. (2007), Competitive marketing strategies of luxury fashion companies[J]. Fashion marketing: Contemporary issues, 16:130-178.

Dogan, V., Ozkara, B. Y., \& Dogan, M. (2018). Luxury consumption tendency: conceptualization, scale development and validation. Current Psychology (1), 1-19.

Dubois, B., Czellar, S., \& Laurent, G. (2005), Consumer segments based on attitudes toward luxury: empirical evidence from twenty countries. Marketing Letters, 16(2), 115-128. 
Guo Yijun \& Su Yong.(2007), Empirical Study on Chinese Luxury Consumption Behavior[J]. Management Review, 19(9): 8-15.

Han Y.J., Nunes J.C., Drèze X. (2010), Signaling Status with Luxury Goods: The Role of Brand Prominence[J]. Journal of Marketing, 74(4):1547-7185.

Howard J.A, Sheth J.N. (1971), The Theory of Buyer Behavior [J]. Journal of the American Statistical Association.

Jones M.A., Reynolds K.E. (2006), Arnold M.J. Hedonic and utilitarian shopping value: Investigating differential effects on retail outcomes[J]. Journal of Business Research, 59(9):974-981.

Julian C.C., Ramaseshan B. (1994), The Role of Customer - contact Personnel in the Marketing of a Retail Bank's Services[J]. International Journal of Retail \& Distribution Management.22(5):29-34.

Kim, J. , \& Lee, H. H. . (2015). Impacts of u.s. affluent consumers।" luxury goods consumption beliefs on repeat purchases of luxury goods: generational and gender comparison analyses. Journal of Global Fashion Marketing, 6(3), 207-221.

Kivenzor, G. , \& Toffoli, R. . (2016). Three Dichotomies of Luxury Consumption in Russia. Thriving in a New World Economy. Springer International Publishing.

Kukar-Kinney, M. , Xia, L. , \& Monroe, K. B. . (2007). Consumers' perceptions of the fairness of pricematching refund policies. Journal of Retailing, 83(3), 325-337.

Lee, J. K. , \& Lee, W. N. . (2009). Country-of-origin effects on consumer product evaluation and purchase intention: the role of objective versus subjective knowledge. Journal of International Consumer Marketing, 21(2), 137-151.

Lichtenstein, D. R. , Netemeyer, R. G. , \& Burton, S. . (1990). Distinguishing coupon proneness from value consciousness: an acquisition-transaction utility theory perspective. Journal of Marketing, 54(3), 54.

Luo Dang. (2014), Research on Consumer Behavior and Motivation of Contemporary Chinese "New Luxury Goods" [D]. Hunan Normal University.

Marcoux, Jean-Sébastien, Filiatrault, P. , \& Chéron, Emmanuel. (1997). The attitudes underlying preferences of young urban educated polish consumers towards products made in western countries. Journal of International Consumer Marketing, 9(4), 5-29.

Mitchell, N. A. . (2014). The impact of luxury brand mentions on consumer culture : a phenomenological inquiry.

Nagashima, A. . (1970). A comparison of japanese and u.s. attitudes toward foreign products. International Executive, 12(3), 7-8.

Roth, M. S., \& Romeo, J. B. (1992). Matching product category and country image perceptions: a framework for managing country-of-origin effects]. Journal of International Business Studies, 23(3), 477-497.

Tidwell P., Dubois B. (1996). A cross-cultural comparison of attitudes toward the luxury concept in Australia and France[J]. International Journal of Physical Education, 44(2): 67-73.

Truong, Y. , Simmons, G. , Mccoll, R. , \& Kitchen, P. J. . (2008). Status and conspicuousness - are they related? strategic marketing implications for luxury brands. Journal of Strategic Marketing, 16(3), 189-203.=

Vickers, J. S. , \& Renand, F. . (2003). The marketing of luxury goods: an exploratory study--three conceptual dimensions. Marketing Review, 3(4), 459-478.

Vigneron, F. , \& Johnson, L. W. . (2004). Measuring perceptions of brand luxury. Journal of Brand Management, 11(6), 484-506.

Xia, L. , Monroe, K. B. , \& Cox, J. L. . (2004). The price is unfair! a conceptual framework of price fairness perceptions. Journal of Marketing, 68(4), 1-15.

Yang, M. , Webster, B. , \& Prosser, M. . (2011). Travelling a thousand miles: hong kong chinese students' study abroad experience. International Journal of Intercultural Relations, 35(1), 69-78.

Yucetepe, \& Veysel. (2003). The moderating role of country-of-destination image on product evaluation: an exploratory study. Ecological Research, 19(5), 485-493.

Zeng Jie. (2006). Research on Factors Affecting Impulsive Purchase Behavior of Chinese Consumers [D]. Sichuan University. 